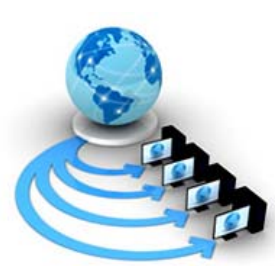

Volume 9, No. 1, January-February 2018

International Journal of Advanced Research in Computer Science

RESEARCH PAPER

\title{
COMPARATIVE STUDY OF SOME MCDM TECHNIQUES FOR E-COMMERCE APPLICATIONS
}

\author{
Sharmistha Roy \\ Department of Computing and Information Technology \\ Usha Martin University \\ Ranchi, India
}

\begin{abstract}
Multi-Criteria Decision Making algorithm is an act of choosing best action among several alternatives. E-commerce application has been widely accepted for business activities because of its low cost and a wide range of coverage. AHP, TOPSIS, and PROMETHEE are some of the Multi Criteria Decision Making techniques popularly accepted to solve the decision problem and record the variations lies in ranking a level. This paper presents a comparative study of some Multi-Criteria Decision Making (MCDM) techniques for ranking, by taking into consideration an E-commerce application as a case study.
\end{abstract}

Keywords: AHP, TOPSIS, PROMETHEE, MCDM, Ranking

\section{INTRODUCTION}

E-commerce is a business model which enables an individual or a firm to conduct business online. E-commerce works on all four major market segments: consumerconsumer, consumer-business, business-consumer, and business-business. E-commerce enables firm or an individual to establish a market or enhance an existing market position over the internet, by providing efficient business chain and low-cost product and service.

The ranking is basically sorting of data in either ascending or descending order providing a clear understanding of the data nature or properties. Since Ecommerce deals with wide range of product it is very hard for a consumer to distinguish the product in need. This can be resolve using the ranking system which enable user to easily distinguish the product efficiency and ranking. Ranking of products is done based on parameters/ criteria that product possess.

Multi criteria decision making (MCDM) is the most wellknown branch of decision making which deals with decision problem under the existence of a number of decision criteria. Ranking of the product is one of the decision problems which can easily be solved using MCDM techniques. This paper provides a significant study on three MCDM techniques AHP, TOPSIS and PROMETHEE II by implementing them on E-commerce applications.

Rest of the paper is organized as follows. Section II describes the literature review of different MCDM algorithms. Section III presents the review of AHP, TOPSIS and PROMETHEE II. Section IV shows the E-commerce application case study. Finally, section V concludes the work.

\section{LITERATURE SURVEY}

In 1980's, T.L. Satty developed AHP (Analytical Hierarchical Process) to provide a hierarchical structure to solve the decision problem and then performs a pair wise comparison [1]. In 1981, Hwang and Yoon developed TOPSIS (Technique for Order Preference by the similarity to Ideal Solution) to enhance the efficiency of decision making methods. TOPSIS ranks the alternatives by finding which one is near to positive solution and far from a negative solution [2]. PROMETHEE was developed by Professor J. Brans in 1982. PROMETHEE is another Multi Criterion Decision Making method which finds best alternatives. It highlights the main alternative by identifying and quantifying the conflicts.

Some of the related work is identified as follows:

Vijay and Shankar (2010) [3], discussed on Facility Location Selection using PROMETHEE II. The goal was to select a location for organization or expansion of an existing facility while considering the important factor such as higher economic benefit, increased productivity and god distributed network. The results show the efficient decision ranking to the problem.

Berna (2012) [4], discussed on financial performance evaluation of technology in Stock Exchange using TOPSIS. The alternatives (firms) were examined and accessed in terms of financial ratios which are combined to obtain a financial performance score. Results show the alternatives are ranked efficiently and were more accurate.

Hanbin, Keith, and Marc (2014) [5], evaluated a source water protection strategies using Grey System Theory and PROMETHEE II. The method uses grey sets to represent uncertain information while considering quantitative and qualitative factors for decision making. Results show that the method is very much reliable for maintaining source water quantity and quality.

Rajat, Gautam and Amit (2015) [6], proposed an algorithm for ranking consumer review on E-commerce website. The algorithm ranks user reviews using content analysis and credibility of the content author. Algorithm also uses a feedback mechanism to improve itself dynamically. Results shows efficiency and enhanced user experience.

Sharmistha et al. (2016) [7], evaluated quality assurance of academic websites using AHP. Paper addresses issues by considering AHP based usability evaluation technique to measure usability score of academic website. Use of AHP results in fulfilling the ranking based on user satisfaction.

Doan and Smet (2016) [8], discussed a preliminary study on the use of reference profiling to compute alternative using PROMETHEE II. Paper proposes a new way to compute an 
alternative ranking that does not suffer from rank reversal. It was observed that ranking is compatible and efficient.

\section{REVIEW OF AHP, TOPSIS, PROMETHEE II}

In this section, a review has been conducted for AHP, TOPSIS and PROMETHEE II.

\section{A. Analytical Hierarchy Process (AHP) [9]}

AHP decomposes the decision problem into criteria, subcriteria, and alternative forming a hierarchy. AHP along with informative data also takes human judgment into account to ensure the efficiency. The steps for implementing AHP process are illustrated below:

Step I: Decompose problem into decision making hierarchy as a goal, alternatives, criteria, and sub-criteria.

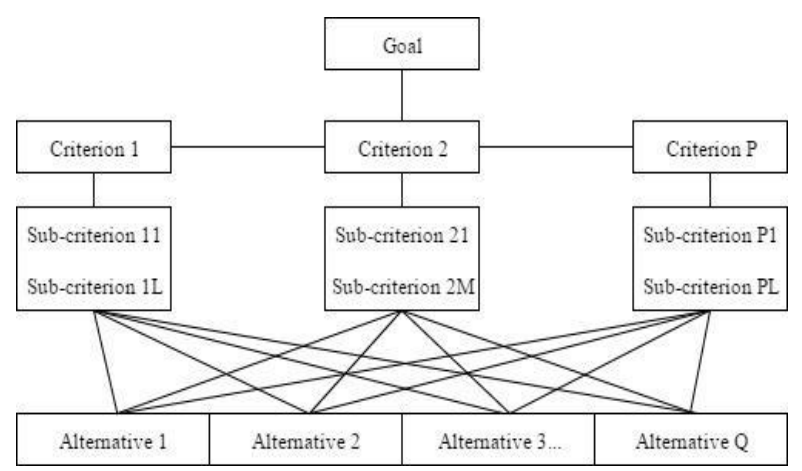

Figure 1. A Scenario of Decision-Making Hierarchy

A

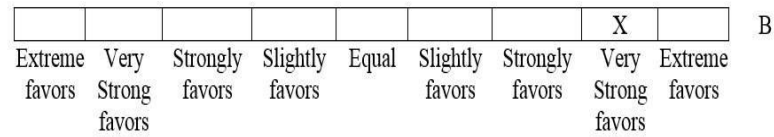

Figure 2. Classification of scale

Step II: Data from the decision problem are applied to the hierarchical structure, as a pairwise comparison using scale given below in table I.

Table I. Satty comparison scale using linguistic value and numeric value

\begin{tabular}{|c|c|}
\hline Linguistic Variable & value \\
\hline Equal & 1 \\
\hline Slightly favors & 3 \\
\hline Strongly favors & 5 \\
\hline Very Strong favors & 7 \\
\hline Extreme favors & 9 \\
\hline Intermediate fuzzy inputs & Reciprocals \\
\hline Reciprocal comparison between \\
inputs
\end{tabular}

Step III: Generate square pairwise matrix using where diagonal elements are 1.

Step IV: Evaluate Eigen value and Eigen vector (weight) for every pairwise matrix.

Step V: To get the final ranking each alternative is multiplied with the weight we got from step IV and then aggregate them.

\section{B. Technique for Order Preference by Similarity to Ideal Solution (TOPSIS) [10]}

TOPSIS ranks the alternative based on the distance between positive and negative ideal solution [5]. The steps for implementing TOPSIS process are illustrated as follow:

Step I: Construct normalized decision matrix.

$$
z_{x y}=\frac{T_{x y}}{\sqrt{\sum_{x=1}^{m} T_{x y}}}
$$

Where, $T_{x y}$ is the evaluation value and $Z_{x y}$ is the normalized value.

Step II: Generate the weighted matrix using weight vector and normalized matrix.

$$
V_{x y}=V_{y} \& Z_{w y}
$$

Where, $\mathrm{W}_{\mathrm{y}}$ is the weight vector.

Step III: Determine the ideal solutions.

$$
T^{t}=\left\{S_{1}^{+}, S_{2}^{+}, \ldots, S_{m}^{+}\right\}
$$

Where,

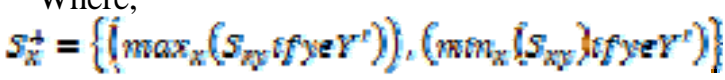

$$
\begin{aligned}
& T^{-}=\left\{S_{1}^{-}, S_{2}^{-}, \ldots, S_{m}^{-}\right\}_{1}
\end{aligned}
$$

Where,

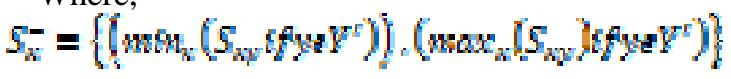

Where,

$\mathrm{T}^{+}$and $\mathrm{T}^{-}$are positive and negative ideal solution respectively.

Step IV: Determine the distance between each alternative from their corresponding ideal solution.

$$
\begin{array}{ll}
T^{+}=\sqrt{\sum_{x=1}^{n}\left(S_{y}^{+}-S_{x y}\right)^{2}} & x=1,2, \ldots m \\
T^{-}=\sqrt{\sum_{y=1}^{n}\left(S_{y}^{-}-S_{x y}\right)^{2}} & x=1,2, \ldots m
\end{array}
$$

Step V: Calculate the corresponding closeness $\mathrm{Q}_{\mathrm{x}}$.

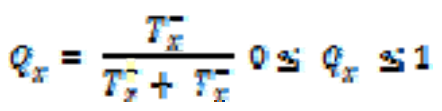

Alternative $Q_{x}$ closest to 1 is the best alternative.

\section{Preference Ranking Organization METHod for Enrichment Evaluation (PROMETHEE) [11]}

PROMETHEE II is a full order outranking technique which provides ranking order to the decision problems. The 
steps for implementing TOPSIS process are illustrated as follow:

Step I: Standardize the evaluation matrix.

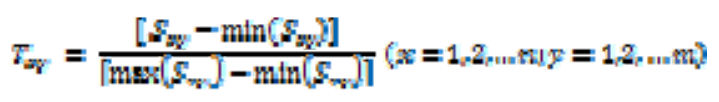

Where, ${ }_{x y}$ is the element of $x^{\text {th }}$ row and $y^{\mathrm{th}}$ column.

Step II: Determine the preference function

$$
\begin{aligned}
& Z_{y}\left(x, X^{\prime}\right)=0 \text { if } T_{x y} \text { s } T_{x t y} \\
& Z_{y}\left(x_{t} X^{t}\right)=\left(T_{w y}-T_{w}\right) t_{j} T_{w y}>T_{w y}
\end{aligned}
$$

Step III: Determine the overall preference function.

$$
\Pi\left(x_{v} x^{i}\right)=\frac{\left[\sum_{y=1}^{m} W_{y} x z_{y}\left(x_{x} x^{i}\right)\right]}{\sum_{y=1}^{m} W_{y}^{k}}
$$

Where, ${ }^{W_{y}}$ is criteria weight for $\mathrm{y}^{\text {th }}$ element.

Step IV: Calculate outranking flow.

$$
\begin{array}{ll}
\varphi^{+}(x)=\frac{1}{\pi-1} \sum_{x^{t}=1}^{n} \pi\left(x_{x} x^{t}\right) & \left(x \neq x^{t}\right) \\
\varphi^{-}(x)=\frac{1}{n-1} \sum_{x^{l}=1}^{n} \pi\left(x_{2}^{t} x\right) & \left(x \neq x^{l}\right)
\end{array}
$$

Where, $\varphi^{+}$is positive or Leaving Flow, $\varphi^{-}$is Negative or Entering Flow and $\mathrm{n}$ is alternatives count.

Step V: Determine the net outranking.

$$
\varphi(x)=\varphi^{+}(x)-\varphi^{-}(x)
$$

Step VI: Calculate the values of $\varphi(x)$ for each alternative. Alternative with highest $\varphi(x)$ value is the best alternative.

\section{E-COMMERCE APPLICATIONS: A CASE STUDY}

To demonstrate work, we have taken one of the Ecommerce application problems from an online automobile shopping. In this problem, we have identified three alternatives (car brand) and three criteria (features) based on which we have to do the ranking. The goal of this problem is to find out the most efficient product based on criteria's. We have applied AHP, TOPSIS and PROMETHEE II methods to determine the comparative result for the decision problem. The decision problem is shown in the table given below.

Table II. Decision-making problem

\begin{tabular}{|c|c|c|c|}
\hline Car & Cost & Safety & Look \\
\hline Ford & 22000 & 28 & Luxury \\
\hline Tesla & 28500 & 39 & Compact \\
\hline
\end{tabular}

\begin{tabular}{|c|c|c|c|}
\hline Toyota & 33000 & 52 & Slick \\
\hline
\end{tabular}

\section{A. Using AHP}

\begin{tabular}{|c|c|c|c|c|}
\hline \multicolumn{5}{|c|}{ Cost } \\
\hline & Ford & Tesla & Toyota & $\mathrm{PV}$ \\
\hline Ford & 1 & 2 & 4 & 0.57 \\
\hline Tesla & $1 / 2$ & 1 & 2 & 0.29 \\
\hline Toyota & $1 / 4$ & $1 / 2$ & 1 & 0.14 \\
\hline \multicolumn{5}{|c|}{ Safety } \\
\hline & Ford & Tesla & Toyota & $\mathrm{PV}$ \\
\hline Ford & 1 & $1 / 2$ & $1 / 5$ & 0.12 \\
\hline Tesla & 2 & 1 & $1 / 4$ & 0.20 \\
\hline Toyota & 5 & 4 & 1 & 0.68 \\
\hline \multicolumn{5}{|c|}{ Look } \\
\hline & Ford & Tesla & Toyota & $\mathrm{PV}$ \\
\hline Ford & 1 & 5 & 9 & 0.76 \\
\hline Tesla & $1 / 5$ & 1 & 2 & 0.16 \\
\hline Toyota & $1 / 9$ & $1 / 2$ & 1 & 0.08 \\
\hline
\end{tabular}

First, we take the decision problem from table II and normalized value according to Satty's comparison scale [12]. Using step II and III we generate square matrix as shown in table III. Finally, step IV and V is applied to get the priority vector and final ranking is shown in table IV.

Table III. Pairwise comparison matrix for Cost, Safety and Look

Table IV. Priority vector and ranking of alternatives

\begin{tabular}{|c|c|c|c|c|c|}
\hline Car & Cost & Safety & Look & Final Weight & Rank \\
\hline Ford & 0.56 & 0.12 & 0.76 & 0.38 & $\mathbf{2}$ \\
\hline Tesla & 0.32 & 0.20 & 0.16 & 0.21 & $\mathbf{3}$ \\
\hline Toyota & 0.12 & 0.68 & 0.08 & 0.41 & $\mathbf{1}$ \\
\hline
\end{tabular}

\section{B. Using TOPSIS}

Using equation 1 and 2, we determine the normalized and weighted decision matrix respectively shown in table V. Then we determine the positive and negative ideal solution using equation 3 and 4 . Finally, using equation 7 relative closeness and ranking is determined as shown in table VI.

Table V. Normalized and Weighted decision matrix

\begin{tabular}{|c|c|c|c|c|c|c|c|}
\hline \multicolumn{4}{|c|}{ Normalized Matrix } & \multicolumn{4}{c|}{ Weighted Matrix } \\
\hline & Cost & Safety & Look & & Cost & Safety & Look \\
\hline & & & & Wi & 0.1 & 0.3 & 0.2 \\
\hline & 0.450 & 0.395 & & & 0.450 & & \\
Ford & 4 & 6 & 0.8452 & Ford & 4 & 0.1187 & 0.1690 \\
\hline & 0.583 & 0.551 & & & 0.583 & & \\
Tesla & 5 & 0 & 0.5071 & Tesla & 5 & 0.1653 & 0.1014 \\
\hline Toyot & 0.675 & 0.734 & & Toyot & 0.675 & & \\
a & 7 & 7 & 0.1690 & a & 7 & 0.2204 & 0.0338 \\
\hline
\end{tabular}

Table VI. Separation difference between ideal solution, relative closeness and ranking

\begin{tabular}{|c|c|c|c|c|}
\hline Alternatives & $\boldsymbol{S}+$ & $\boldsymbol{S}$ - & Relative Closeness & Rank \\
\hline Ford & 0.2472 & 0.1352 & 0.3536 & $\mathbf{3}$ \\
\hline Tesla & 0.1269 & 0.1564 & 0.5521 & $\mathbf{2}$ \\
\hline Toyota & 0.1352 & 0.2472 & 0.6468 & $\mathbf{1}$ \\
\hline
\end{tabular}




\section{Using PROMETHEE II}

First, we normalized the evaluation matrix using equation 8. Then we determine the pairwise preference function using equation 9 and 10. Finally outranking flow and net outranking is determined using equation 12, 13 and 14. Final result is shown in table VIII.

Table VII. Objective data and normalized decision matrix

\begin{tabular}{|c|c|c|c|c|c|c|c|}
\hline \multicolumn{4}{|c|}{ Evaluation Matrix } & \multicolumn{4}{|c|}{ Normalized Matrix } \\
\hline & Cost & $\begin{array}{c}\text { Safet } \\
y\end{array}$ & Look & & Cost & $\begin{array}{c}\text { Safet } \\
y\end{array}$ & Look \\
\hline Ford & $\begin{array}{c}2000 \\
0\end{array}$ & 28 & Luxury/5 & Ford & 0 & 0 & 1 \\
\hline Tesla & $\begin{array}{c}2850 \\
0 \\
\end{array}$ & 39 & $\begin{array}{c}\text { Compact/ } \\
3 \\
\end{array}$ & Tesla & 0.591 & 0.458 & 0.5 \\
\hline Toyota & $\begin{array}{c}3300 \\
0\end{array}$ & 52 & Slick/1 & Toyota & 1 & 1 & 0 \\
\hline
\end{tabular}

Table VIII. Outranking flow and Net Outranking

\begin{tabular}{|c|c|c|c|c|}
\hline Car & Entering Flow & Leaving Flow & Net Outranking & Rank \\
\hline Ford & 0.25 & 0.4973 & -0.2473 & 3 \\
\hline Tesla & 0.2473 & 0.2528 & -0.006 & 2 \\
\hline Toyota & 0.5028 & 0.25 & 0.2528 & $\mathbf{1}$ \\
\hline
\end{tabular}

\section{FINDS ON RANKING LEVELS}

After applying AHP, TOPSIS and PROMETHEE II technique to our E-commerce problem, we have derived the following results as shown in table IX.

Table IX. Final Alternative Ranking of all three methods

\begin{tabular}{|c|c|c|c|}
\hline Alternatives & AHP & TOPSIS & PROMETHEE II \\
\hline Ford & 2 & 3 & 3 \\
\hline Tesla & 3 & 2 & 2 \\
\hline Toyota & 1 & 1 & 1 \\
\hline
\end{tabular}

\section{E. DISCUSSION}

From the above result it is clear that all the three techniques are quite successful in providing the better and effective ranking to the alternatives. However, AHP ranking differs from TOPIS and PROMETHEE II ranking. As we can see from the above result, for car Ford and Tesla AHP has ranking 2 and 3 respectively whereas, TOPSIS and PROMETHEE II is vice versa. AHP uses complex comparison matrix for all its criteria and alternatives which leads to higher efficiency [13] whereas TOPSIS and PROMETHEE II [14] uses simple techniques to achieve ranking goals.

\section{CONCLUSION}

AHP is most widely used MCDM technique to solve decision problem. It uses comparison matrix for all its criteria, sub-criteria and alternatives to provide ranking. TOPSIS provides ranking to the alternatives by finding which one is near to positive ideal solution and which one far from negative ideal solution. PROMETHEE is an outranking technique, it identifies and quantifies the decision conflict and provide ranking to the decision problem. The work concludes with followings:

We have identified the variation in result while solve Ecommerce decision problem using all three techniques. The result shows efficiency for solving any decision problem using these techniques though result may vary from technique to technique. This comparative study helps us to understand the underlying process behind each of the technique and their capabilities.

A hybrid model which consists of AHP, TOPSIS and PROMETHEE II will be included as future scope of the work.

\section{REFERENCES}

[1] T.L. Saaty, “The Analytical Hierarchy Process”, Tata McGraw Hill, New York, 1980.

[2] Y. J. Lai, T. Y. Liu, C. L. Hwang, "TOPSIS for MODM”, European Journal of Operational Research 76 (3) 486-500, 1994.

[3] V.M. Athawle, S. Chakraborty, "Facility Location Selection using PROMETHEE II Method”, ICIEOPM, 2010.

[4] B. Bulgurcu, "Application of TOPSIS techniques for financial performance evaultion of technology firms stock exchange market”, 62, 1033-1040, 2012.

[5] H. Kuang, K.W. Hipel, D.M. Kilgour, "Evaluation of source water protection strategies in Waterloo Region based on Grey Systems Theory and PROMETHEE II”, IEEE International Conference, 10.1109/ICSMC.2012.6378168, 2012.

[6] R. Sharma, G. Nagpal, A. Kanwar, "Algorithm for Ranking Consumer Reviews on E-commerce Websites”, International Journal of Computer Science and Information Technologies, 6(6), 4878-4881, 2015.

[7] S. Roy, P.K. Pattnaik, R. Mall, "Quality assurance of academic websites using usability testing: an experimental study with AHP”, International Journal of System Assurance Engineering and Management, vol. 8, no. 1, pp. 1-11, 2017.

[8] N.A.V. Doan and Y. De Smet, "On the use of reference profiles to compute alternative PROMETHEE II rankings: A preliminary study”, IEEE, 2157-362, 2016.

[9] P.T. Harker, "The art of Science and Decision-making: The Analytic Hierarchy Process”, Springer Verlag, 1989.

[10] M.C Lin, C.C wang, M.S Chen, C.A. Chang, "Using AHP and TOPSIS approaches in customer-driven product design process”, Comput Industry 59 (1), 17-31, 2007.

[11] S. Mousavi, M.R.M Tavakkoli, M. Heydar, S. Ebrahimnejad, "Multi-Criteria Decision Making for Plant Location Selection: an Integrated Delphi-AHPPROMETHEE Methodology”, Arab J Sci Engg. 38 (5), 1255-1268, 2012.

[12] T.L. Saaty, "Exploring interface between Hierarchies, multiple objectives and Fuzzy sets”, Fuzzy sets and systems, vol. 1, 57-68, 1978.

[13] M. Dagdeviren, S. Yavuz, N. Kilinc, "Weapon selection using the AHP and TOPSIS methods under fuzzy environment”, Expert Syst Appl, vol. 36, 8143-8151, 2009.

[14] H. Kuang, K.W. Hipel, D.M. Kilgour, "Evaluation of source water protection strategies in Waterloo Region based on Grey Systems Theory and PROMETHEE II”, IEEE International Conference on Systems, Man, and Cybernetics (SMC), 2775-2779, 2012. 